\title{
ETIDOCAINE: A CLINICAL EVALUATION FOR REGIONAL ANALGESIA IN SURGERY
}

\author{
P.R. BROMAGE, M.B., B.S., F.F.A.R.C.S., F.R.C.P.(C), P. O'BEIRN, M.B., B.CH., D.A., \\ AND LORNA A. DUNFORD, S.R.N., R.S.C.N."
}

Small alterations of structure in a local anaesthetic molecule may produce large changes in physicochemical properties and clinical performance. Etidocaine or "Duranest ${ }^{*}$ " is a xylidide derivative with a structure similar to lidocaine, but with two small modifications to convert it to 2-(N-ethylpropylamino)-2',6'butyroxylidide. The formulae for lidocaine and etidocaine are shown for comparison in Figure 1.

These relatively slight alterations in the lidocaine molecule confer a 50 per cent increase in its protein binding power, and a 50-fold increase in lipid solubility, producing a local anaesthetic agent with the unusual properties of rapid onset combined with a very long duration. Preliminary investigations by others in animals and man have shown that etidocaine is neither irritating nor prone to produce methaemoglobinaemia. The drug is rapidly taken up and redistributed in body tissues, and blood concentrations fall rapidly. Its toxicity is reported to be less than bupivacaine, and about four to four-and-a-half times that of lidocaine. ${ }^{1,2}$ Subjective signs of toxicity appear at blood concentrations of about $2.0 \mu \mathrm{g} / \mathrm{ml}$. Lund found that this level was not exceeded by epidural doses of up to $300 \mathrm{mg} .^{3}$

Etidocaine was investigated in 232 surgical patients, with particular attention to speed of onset of analgesia, duration of action in epidural and peripheral nerve blocks, quality of sensory and motor blockade and segmental dose requirements for lumbar and thoracic epidural blockade.

\section{METHODS}

Regional anaesthesia was administered to 232 lightly premedicated patients scheduled for routine surgical operations. Ages ranged between 18 and 90 years: all patients were free from neurological disease. The distribution of cases and analgesic solutions are shown in Table I.

\section{Epidural Blockade}

Epidural puncture was performed with the patients in the sitting position. The following intervertebral sites were chosen according to surgical indications: 6 th thoracic for upper abdominal cases; 2nd lumbar for lower abdominal cases; 3rd or 4th lumbar for inguinal, lower limb or perineal surgery. A 17-gauge Tuohy

\footnotetext{
-Departments of Anaesthesia, Royal Victoria Hospital and McGill University, Montreal, Canada.
} 
<smiles>CCN(CC)CC(=O)NC1C(C)CCCC1C</smiles><smiles></smiles>

Figure 1. Structural formulae for lidocaine and etidocaine.

TABLE I

Etidocaine Hydrochloride ("Duranest") in Regional Anaesthesia for Surgery Distribution OF 232 CASES

\begin{tabular}{|c|c|c|}
\hline Solution of Etidocaine & Site & No. \\
\hline $\begin{array}{l}1 \% \text { Plain } \\
1 \%+\text { Epinephrine } 1 / 200,000 \\
1 \%+\text { Epinephrine } 1 / 200,000 \\
1 \%+\text { Epinephrine } 1 / 200,000 \\
1 \%+\text { Epinephrime } 1 / 200,000 \\
1 \%+\text { Epinephrine } 1 / 200,000 \\
0.5 \%+\text { Epinephrine } 1 / 200,000\end{array}$ & $\begin{array}{l}\text { Lumbar Epidural } \mathrm{L}_{2}-\mathrm{L}_{3} \\
\text { Thoracic Epidural } \mathrm{T}_{6}-\mathrm{T}_{7} \\
\text { Lumbar Epidural } \mathrm{L}_{2}-\mathrm{L}_{3} \\
\text { Lumbar Epidural } \mathrm{L}_{3}-\mathrm{L}_{4} \\
\text { Lumbar Epidural } \mathrm{L}_{4}-\mathrm{L}_{5} \\
\text { Caudal } \\
\text { Supraclavicular Brachial Plexus }\end{array}$ & $\begin{array}{l}20 \\
41 \\
76 \\
17 \\
37 \\
5 \\
36\end{array}$ \\
\hline
\end{tabular}

needle was employed for lumbar epidurals, using the midline approach, and the loss-of-resistance test. An 18-gauge thin-walled Bromage needle was chosen for thoracic punctures, using an oblique paravertebral approach and the "hangingdrop" sign of Gutierrez.

An induction dose of 1 per cent etidocaine was given as a single injection through the epidural needle in every case, and a catheter was then inserted in a cephalad direction. The induction dose varied between $4 \mathrm{ml}$ and $32 \mathrm{ml}$, depending on age, clinical requirements and site of injection. Speed of injection was in the range of $0.75 \mathrm{ml}-1.0 \mathrm{ml}$ per second. Subsequent maintenance doses were restricted to half of the induction dose and were given through the epidural catheter. 
The onset and spread of cutaneous analgesia was determined by pin-prick at frequent intervals, using a 22-gauge needle, and a segment time diagram of the area of analgesia was charted in every case. ${ }^{4}$

Motor blockade of the legs was assessed and scored for each leg by a scale used in previous investigations. ${ }^{5}$ Complete inability to move the leg or foot was counted as "complete block" ( 100 per cent). Ability to move the foot but not the knee or hip was "almost complete" (66 per cent), partial impairment of knee flexion was "partial" ( 33 per cent), and unimpaired knee and ankle movements was "nil" (0 per cent).

Duration of blockade was measured in two ways. First, as regression of two segments; that is, the time from complete onset and spread of analgesia until the segmental span of anaesthesia had diminished by two dermatomes on each side. Second, complete duration; that is, the time from complete spread of analgesia until analgesia had regressed in all affected segments. "Complete duration" was not scored in every case because postoperative analgesia was usually reinstated for clinical reasons after analgesia had receded two segments.

\section{Brachial Plexus Block}

Supraclavicular brachial block was performed by Patrick's approach, with a 23-gauge needle. Forty-five $\mathrm{ml}$ of 0.25 per cent etidocaine and $1 / 200,000$ epinephrine were injected into the neurovascular sheath on the first rib. Latency of anaesthesia was measured from the moment of commencing injection, and the onset of anaesthesia was charted for the areas of cutaneous distribution of the musculocutaneous, radial, median and ulnar nerves, as in a previous communication. ${ }^{6}$

\section{Results}

\section{Epmural Anaesthesia}

No complications or dural punctures were encountered in 191 epidural blocks.

\section{Latency}

(a) Etidocaine plus epinephrine $1 / 200,000$

The latency of onset of mid-thoracic and lumbar epidural block is shown in a composite segment-time diagram in Figure 2. Each dot represents one individual observation of an upper or lower level of analgesia, and the average latency profiles are drawn through the data points. The average onset is rapid, with a mean time of 10.85 minutes for complete spread in all segments below $T_{4}$, but there is considerable variability, particularly in the lumbar segments. There is also a tendency for anaesthesia to be delayed in the fifth lumbar and first sacral segments when injection is made at the second lumbar interspace. A similar delayed salient at $L_{5}$ and $S_{1}$ has been observed to a greater or lesser degree in the latency profiles of all other local anaesthetic agents tested, but it should be noted that etidocaine exhibits this tendency to a comparatively slight degree. ${ }^{?}$

Changing the site of puncture downwards from the second to the fourth lum. bar interspace produced a somewhat modified latency profile with a faster and 
EPIDURAL ONSET PROFILES : $1 \%$ ETIDOCAINE
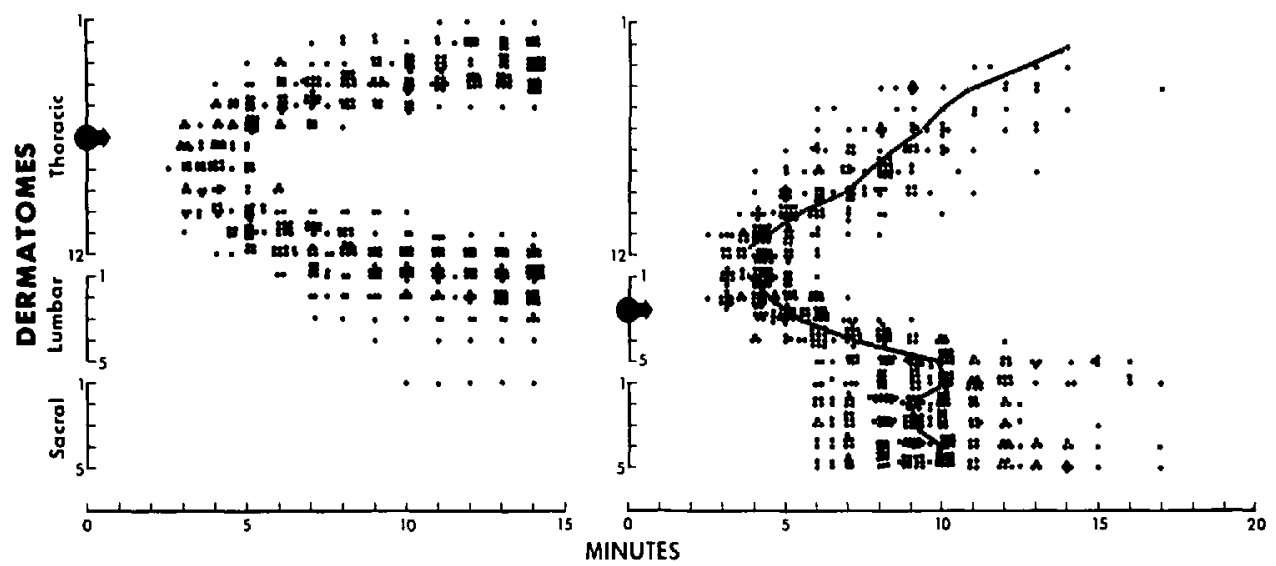

Figure 2. Epidural latency profiles for 1 per cent etidocaine at the 6th thoracic and 2nd lumbar interspaces.

more predictable onset of anaesthesia in the sacral segments. With a puncture in the mid-thoracic region it was possible to confine the segmental area of anaesthesia to the abdominal and adjacent dermatomes. Onset of anaesthesia at this level was rapid and complete within 10-12 minutes, as shown in Figure 2.

\section{(b) Etidocaine plain}

The onset and spread of analgesia with plain etidocaine was markedly slower than with the epinephrine-containing solution, and the mean time for complete spread was 18 minutes in the 15 cases tested.

\section{Dose Requirements}

The anaesthetic dose required, expressed as the mass of drug required for each spinal segment was calculated in every case by dividing the dose in milligrams by the number of analgesic dermatomes. The results are shown graphically in Figure 3. Dose requirements declined in a linear manner between 18 and 90 years and were inversely proportional to age, as has been found with all other agents tested in this way. $4,5.7$ Lumbar dose requirements for 1 per cent etidocaine with epinephrine were $17.5 \mathrm{mg}$ per segment at 20 years, declining to $7.0 \mathrm{mg}$ at 80 years. These figures are approximately half the dose requirements for lidocaine, and about twice the requirements for bupivacaine. Dose requirements were about 10 per cent less with plain etidocaine than with the epinephrinecontaining solution, but the difference was not significant.

No significant difference in dose requirements was caused by altering the site of lumbar injection from the second to the third or fourth lumbar interspaces. However, with midthoracic injection relatively small doses were required, and in this series the amounts varied between $4 \mathrm{ml}(40 \mathrm{mg}$ ) for a man of 87 years, to $16 \mathrm{ml}(160 \mathrm{mg})$ for a 20 -year-old. From Figure 3 it can be seen that segmental dose requirements with mid-thoracic puncture were about 30 per cent less than with lumbar injection. 


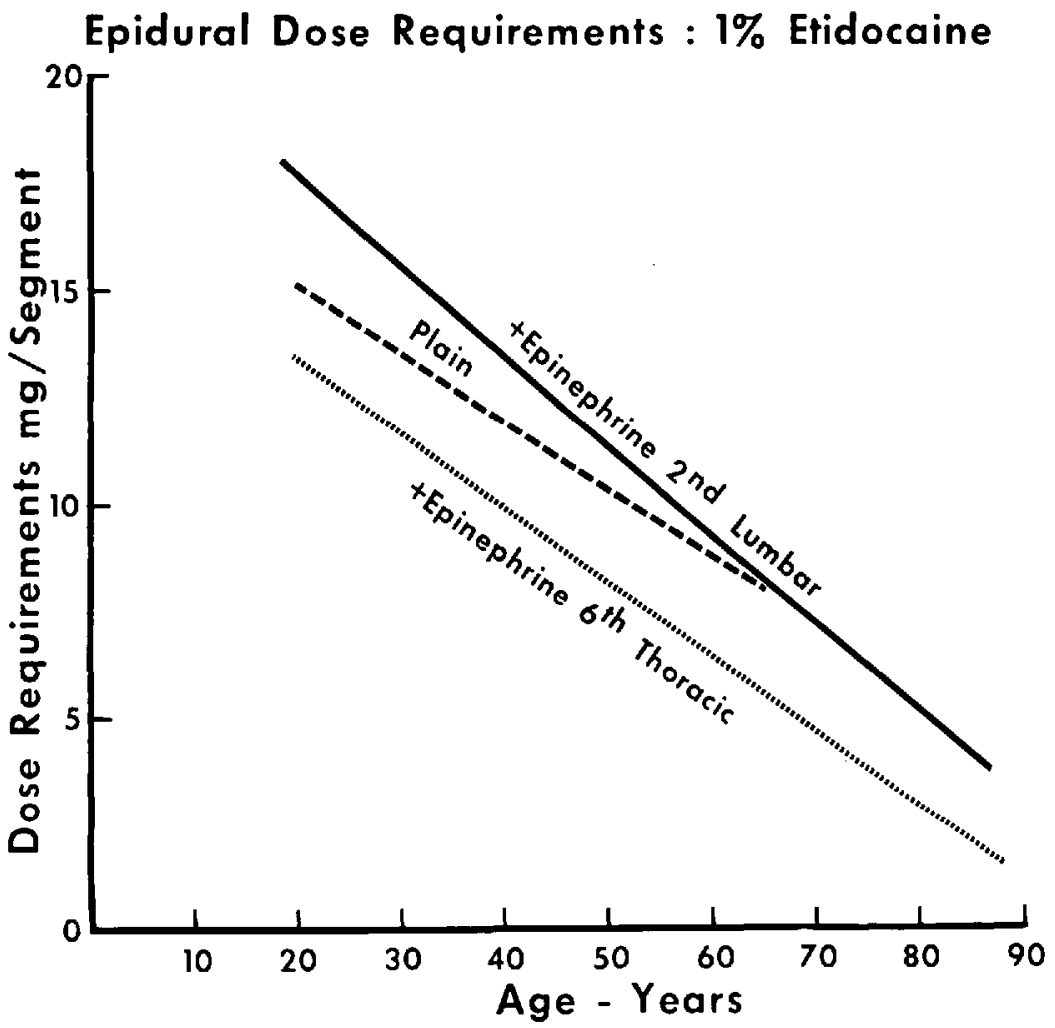

Figure 3. Epidural dose requirements for 1 per cent etidocaine at the 2 nd lumbar and 6th thoracic interspaces.

\section{Quality of Blockade}

The plain solution gave inferior sensory analgesia and less motor block than when epinephrine $1 / 200,000$ was added. The average degree of motor block was intense, with a score of almost 60 per cent for the epinephrine solution, and 50 per cent for the plain solution. These values represent the most profound intensity of motor paresis that we have encountered among any of the local anaesthetic agents tested for epidural blockade in our department. Comparative figures for other agents are shown in Table II.

The quality of cutaneous analgesia with the epinephrine-containing solutions was satisfactory and no patchy or "missed segments" were encountered in this series. However, there was an impression that visceral sensation was less effectively blocked than with certain other agents such as bupivacaine or carbonated lidocaine. The plain solution without epinephrine produced less satisfactory analgesia and segmental spread tended to be slow and patchy.

\section{Duration of Sensory Blockade}

The duration of action of etidocaine varied widely in both the thoracic and lumbar regions and appeared to be dose related. The range of duration for recession of two segments lay between 70 minutes and 290 minutes, with a mean of 
$172 \pm 57$ minutes for the lumbar blocks, and $145 \pm 44$ minutes for the thoracic blocks. A shorter duration for thoracic blocks had been noted in a previous series using bupivacaine, and the difference was assumed to be due to the smaller mass of drug required for thoracic blocks. However, the difference is barely significant in this series owing to the very large variance at both sites.

\section{Toxicity}

No evidence of systemic toxicity was seen in this series. Some degree of transient back pain was generally encountered at the site of injection when I per cent etidocaine with epinephrine was used for epidural analgesia. This local pain is probably attributable to acidity rather than true toxicity, since the $\mathrm{pH}$ of the epinephrine containing solution was low $(\mathrm{pH}=3.92)$. The plain solution was less acid ( $\mathrm{pH}=4.37$ ) and caused less local pain.

\section{Brachial Plexus Blockade}

A scattergram for onset in the cutaneous distribution of the brachial plexus is shown in Figure 4. The mean onset was rapid in all cutaneous nerves but it can be seen that latency was somewhat unpredictable. In some cases, onset of blockade was extremely rapid and the arm was totally insensitive and paralysed before the needle was withdrawn, while in other cases more than 17 minutes elapsed before blockade was complete, even after a technically accurate injection accompanied by unequivocal paraesthesiae of the hand.

The quality of anaesthesia with 0.5 per cent etidocaine was intense and satisfactory for all tissues of the hand and forearm. No complaints were encountered during work on bone or joint structures, and motor block was complete in every case.

Blockade persisted for an impressively long time, and in some instances lasted 20 hours, with a mean duration of nine and a half hours. The variation was wide and unpredictable and in some cases the anaesthetic effects wore off as early as four hours after injection, despite a technically perfect block with rapid onset and profound anaesthesia. The cause of this great variation is unexplained and there is no relationship between duration and age. Nor was there any relation between duration and dose in brachial plexus blockade in this series, since the same dose was used in each patient.

\section{Discussion}

The protocol of investigation in this study has been applied to other agents under similar conditions, and with similar criteria for clinical performance. Certain quite specific comparisons can reasonably be made and these are outlined in Table II.

Etidocaine is remarkable for three qualities: rapid onset, long duration, and intense motor block. The simultaneous properties of short latency and long duration represent a welcome and unexpected departure from experience with other long-acting agents such as dibucaine, tetracaine and bupivacaine, where the physicochemical properties conferring long duration also confer slow latency. 


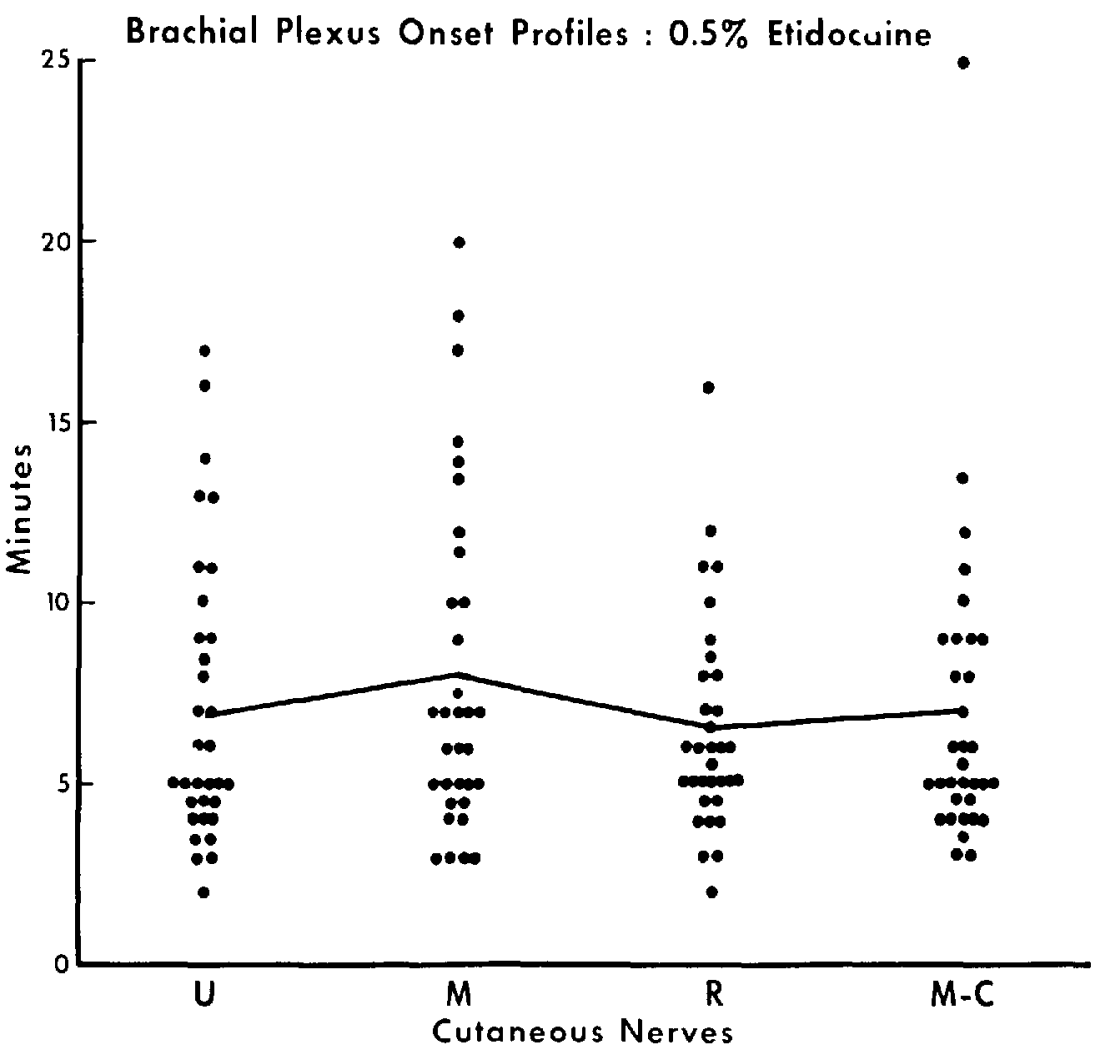

Figure 4. Latency of onset of supraclavicular brachial plexus block with 0.5 per cent etidocaine $+1 / 200,000$ epinephrine.

$$
\begin{aligned}
& \mathrm{U}=\text { Ulnar } \\
& \mathbf{R}=\text { Radial } \\
& \mathrm{M}=\text { Median } \\
& \mathrm{M}-\mathrm{C}=\text { Musculocutaneous }
\end{aligned}
$$

The solid line indicates the average latency for each cutaneous nerve.

The unusually high lipid-solubility and strong protein-binding of etidocaine appear to be important determinants for rapid and firm attachment to neural target sites and their coverings. Latency was quite variable, but the means for both epidural and brachial block with the epinephrine solutions were shorter than for any other agent shown in Table II, with the exception of carbonated lidocaine, and there is a 98 per cent chance that epidural block will be complete within 15 minutes of injection. This attribute of rapid onset places etidocaine in a more practical category than tetracaine or bupivacaine for routine daily use in a busy surgical environment.

Etidocaine was designed as a long-acting clinical agent and the mean duration of 172 minutes for epidural block makes it a close runner-up to bupivacaine in this respect, while the mean duration of 573 minutes for brachial block is almost identical to bupivacaine.

Without an added vasoconstrictor etidocaine performed relatively poorly, but latency, quality of blockade and duration were all markedly improved by adding $1 / 200,000$ epinephrine. Also, the plain solution produced a more extensive seg- 
mental block than the epinephrine solution, with each segment receiving a smaller dose of the agent (see Figure 2). This suggests that the clinical performance of epidural blockade is partially determined by the amount of drug taken up at each segment.

Our dose requirement data shows that the potency of etidocaine in the epidural space is about twice that of lidocaine ( see Table II). The toxicity of lidocaine in this situation has not been determined, although studies in animals by Adams and his colleagues suggest that etidocaine has about twice the toxicity of lidocaine when injected subcutaneously. ${ }^{1}$ However, Munson et al. have shown that etidocaine is four and a half times as toxic as lidocaine when injected intravenously. ${ }^{2}$ Thus, an important factor in the apparent toxicity of etidocaine is the relative speed of its absorption and uptake into available volumes of the vascular space and lipid stores respectively. Quite large doses are likely to be well tolerated and safely absorbed in the fatty purlieus of the epidural space, but rapid injection made accidentally into a vein will be disproportionately toxic.

This series has not revealed any way of predicting the duration of brachial plexus anaesthesia and the range was extremely wide, between 4 hours and 20 hours. Age is not correlated with duration, nor is technical accuracy and speed of onset. Some brachial blocks seemed perfect in execution, and almost instantaneous in onset, and yet anaesthesia lasted barely 4 hours, while some others with much slower onset lasted more than 15 hours.

The unpredictable temporal behaviour of etidocaine at a peripheral site is contrasted with its highly dependable characteristics of onset and spatial spread, and intensity of motor blockade in the epidural space. Epidural dose requirements can be foretold with remarkable accuracy. The correlation coefficient for age and segmental dose requirements is highly significant $(r=0.916)$ while the 95 per cent confidence limits of the population are narrower and more predictable than for bupivacaine and tetracaine. Moreover, cutaneous anaesthesia was even and dependable, and no dermatomes escaped within the segmental distribution of blockade. Anaesthesia of deeper structures, particularly within the peritoneal cavity, was more difficult to assess, but there was a clinical impression that visceral anaesthesia was less satisfactory, as traction on abdominal contents frequently elicited painful responses. On the other hand, motor block was remarkably intense, with the highest score for all the anaesthetic agents tested as shown in Table II. Flaccid paralysis of the legs was the rule rather than the exception after lumbar blockade, and intercostal paralysis was common after mid-thoracic injection. The association of powerful motor blockade with somewhat less impressive sensory anaesthesia is reminiscent of tetracaine, which also produces a very high degree of motor block with a relatively indifferent quality of pain relief. In contrast, bupivacaine shows the reverse association, with superior analgesic qualities, but a milder degree of motor paralysis. This phenomenon of dissociation between the degree of motor and sensory blockade has been observed before, ${ }^{7}$ but it is difficult to explain in terms of fibre size in the posterior nerve roots. Normally, one would expect that a strong degree of motor paralysis from large fibre involvement would be associated with a comparably effective block in all fibres of the same or smaller calibre and that afferent block would be 
equally intense. But here we find a lack of the expected association; on the one hand we have bupivacaine with relatively good sensory anaesthesia, but poor motor blockade, and on the other tetracaine and etidocaine with strong blockade of large motor pathways but relatively weak sensory block. The quality of sensory anaesthesia with etidocaine seems to be superior to tetracaine, with faster onset and fewer missed segments in epidural anaesthesia, but the intensity of motor blockade is disquietingly severe. High epidural blocks with 1 per cent etidocaine are unsuited to maximal respiratory performance, while lower blocks make early postoperative movements and exercises of the lower limbs either ineffectual, or frankly impossible.

This apparent disparity between the quality of sensory and motor blockade might be explained by action at the level of the spinal cord in terms of architectonic involvement, if it could be shown that different local anaesthetic agents affected different parts of the spinal white and grey matter to varying degrees. ${ }^{8}$ This possibility seems quite attractive, since it has been shown that local anaesthetics do penetrate into the substance of the spinal cord from both the subarachnoid space and from the epidural space."10 Moreover, one of us (P.R.B.) has found that lower limb reflexes develop an upper motor neurone pattern of response more frequently after a thoracic segmental block with etidocaine than with lidocaine or bupivacaine. This could be interpreted as reflecting deeper penetration of the cord and more selective involvement of long spinal pathways by etidocaine than by the other two agents. It also suggests that architectonic analysis of local anaesthetic uptake in the cord might prove a useful tool for screening new local anaesthetic drugs in animals before proceeding to clinical trial in humans. ${ }^{11}$

Certain practical conclusions may be drawn from the present analysis:

1. Etidocaine with epinephrine is a clinically useful agent for peripheral nerve block, with a rapid and powerful action, and a long but unpredictable duration that may last anywhere between 4 hours and 20 hours. Therefore, it is suitable for inpatient surgery, but less suited for ambulatory outpatient surgery where possible prolonged blockade may be inconvenient, or even dangerous if it masks signs of untoward surgical complications.

2. The agent is rapidly acting and moderately long lasting in the epidural space, where the great predictability of its segmental spread makes it well suited for single-shot injections. However, the intense degree of motor paralysis with 1 per cent etidocaine precludes early postoperative movements and exercises. The propensity for excessive motor blockade is likely to be a disadvantage in obstetrical anaesthesia, and the feasibility of more dilute concentrations for pain relief in labour will be reported in the next paper.

\section{SUMMARY}

The new long-acting local anaesthetic etidocaine ("Duranest", Astra) was assessed for regional analgesia using a qualitative and quantitative scoring system established for other local anaesthetic agents. Two hundred and thirty-two blocks were performed, using 1 per cent etidocaine for 196 epidural anaesthetics, and 
0.5 per cent etidocaine with $1 / 200,000$ epinephrine for 36 cases of supraclavicular brachial plexus blockade. No untoward reactions or dural punctures were encountered in this series.

Analgesia developed rapidly in both epidural and brachial plexus blockade. The mean latency for lumbar epidural block was 10.85 minutes, and 8.7 minutes for supraclavicular block. The segmental spread of epidural analgesia was highly predictable, and segmental dose requirements were 50 per cent less than those needed for lidocaine. Motor block was intense, and complete immobility of the legs usually accompanied lumbar epidural analgesia. The duration of blockade was rather unpredictable and a wide variance was encountered with both epidural and brachial plexus analgesia. The mean duration for recession of two segments in epidural analgesia was 170 minutes (S.D. $= \pm 57$ minutes), while the mean duration of brachial plexus blockade was 572 (S.D. $= \pm 203$ minutes). The quality of epidural blockade was markedly influenced by the presence or absence of a vasoconstrictor. One per cent plain etidocaine gave slower onset of epidural analgesia, shorter duration and less intense quality of sensory and motor blockade than the solution with $1 / 200,000$ epinephrine.

The practical applications of etidocaine for regional analgesia are discussed in the light of these findings.

\section{RÉSUMÉ}

Utilisant un système de cotation qualitatif et quantitatif conçu pour des travaux déjà publiés (5), nous avons évalué un nouvel agent anesthésique local: l'Etidocaine (Duranest, Astra). Nous avons exécuté 232 blocages régionaux répartis comme suit: 196 anesthésies péridurales avec un solution à 1 pour cent et 36 blocages du plexus brachial par voie supraclaviculaire avec une solution à 0.5 pour cent additionnée d'Epinéphrine à 1 pour 200,000. Dans cette série, jamais, la dure-mère fut-elle ponctionnée par inadvertance ni aucun effet indésirable n'est-il survenu.

L'apparition de l'analgésie fut rapide dans les deux groupes: le délai moyen était de 10.85 min pour le blocage péridural et 8.7 minutes pour le blocage supra-claviculaire.

On pouvait prédire avec certitude l'extension segmentaire de l'anesthésie péridurale et la posologie par segment était la moitié de celle de la Lidocaine. Le blocage moteur était intense et interdisait tout mouvement des membres inférieure à la suite de l'anesthésie péridurale. La durée du blocage cependant était imprévisible et on a noté de grandes différences dans les deux types de blocage. L'épuisement de l'analgésie portant sur deux segments s'est opéré en moyenne en 170 minutes (D.S. $= \pm 57 \mathrm{~min}$ ) alors que les blocages brachiaux pour leur part, ont persisté pendant 572 minutes (D.S. $= \pm 203$ minutes). La présence ou l'absence de vasoconstricteurs dans la solution modifiait profondément la qualité du blocage: avec l'Etidocaine nature, le blocage péridural est d'apparition plus lente, dure moins longtemps et est de moindre intensité dans ses composantes tant sensorielle que motrice.

Nous présentons en terminant les conséquences pratiques de ces constatations. 


\section{ACKNOWLEDGMENTS}

Thanks are due to Astra Chemicals Inc. for a grant in support of this study and also for supplies of etidocaine. Dr. R. Fynes kindly assisted with statistical processing of data.

\section{REFERENCES}

1. Adams, H.J., Kronberc, G.H., \& TAKMan, B.G. Local anesthetic activity and acute toxicity of $( \pm)-2-\mathrm{N}$-ethylpropylamino $)-2^{\prime}, 6^{\prime}$ butyroxylidide, a new long-acting agent. J. Pharm. Sci. 61: 1829-1831 (1972).

2. Munson, E.S., Tucken, W.K., \& EMrro, B.S. Etidocaine and lidocaine induced seizures in Rhesus monkeys. Abstr. A.S.A. Annual Meeting, San Francisco 1973, p. 173.

3. Lund, P.C., CWIK, J.C., \& PAgdanganan, R.T. Etidocaine - a new long-acting local anesthetic agent: a clinical evaluation. Anesth. \& Analg. 52: 482-493 (1973),

4. Bromage, P.R. Spread of analgesic solutions in the epidural space and their site of action: a statistical study. Brit. J. Anaesth. 34: 161-178 (1962).

5. BROMAgE, P.R. A comparison of the hydrochloride and carbon dioxide salts of lidocaine and prilocaine in epidural analgesia. Acta anaesth. scandinav. Suppl. 16, 55-69 (1965).

6. Bromage, P.R. \& Gertel, M. Improved brachial plexus blockade with bupivacaine hydrochloride and carbonated lidocaine. Anesthesiology 36:479-487 (1972).

7. BROMAGE, P.R. A comparison of bupivacaine and tetracaine in spidural analgesia for surgery. Canad. Anaesth. Soc. J. 16: 37-45 (1969).

8. REXED, B. Some aspects of the cytoarchitectonics and synaptology of the spinal cord. Prog. in Brain Res. 11: 58-90 (1964).

9. Bromage, P.R., Joyal, A.C., \& BinneY, J.C. Local anesthetic drugs: penetration from the spinal extradural space into the neuraxis. Science 140: 392-394 (1963).

10. Conen, E.N. Distribution of local anesthetic agents in the neuraxis of the dog. Anesthesiology 29: 1002-1005 (1968).

11. Bromace, P.R. Reflex changes in segmental epidural analgesia. Brit. J. Anaesth. Awaiting publication.

12. Bromage, P.R., Burfoot, M.F., Crowell, D.E., \& Pettignew, R.T. Quality of epidural blockade I: Influence of physical factors. Brit. J. Anaesth. 36: 342-352 (1964). 